\title{
Article
}

\section{Prioritising lower limb health}

\author{
Ritchie, Georgina Louise
}

Available at http://clok.uclan.ac.uk/32624/

Ritchie, Georgina Louise (2020) Prioritising lower limb health. British Journal of Community Nursing, 25 (3). S5-S5. ISSN 1462-4753

It is advisable to refer to the publisher's version if you intend to cite from the work.

10.12968/bjcn.2020.25.sup3.s5

For more information about UCLan's research in this area go to

http://www.uclan.ac.uk/researchgroups/ and search for < name of research Group>.

For information about Research generally at UCLan please go to http://www.uclan.ac.uk/research/

All outputs in CLoK are protected by Intellectual Property Rights law, including Copyright law. Copyright, IPR and Moral Rights for the works on this site are retained by the individual authors and/or other copyright owners. Terms and conditions for use of this material are defined in the policies page.

\section{CLoK}

Central Lancashire online Knowledge www.clok.uclan.ac.uk

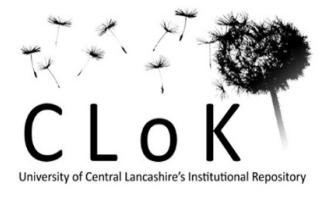


Recognising lower limb health is a priority.

It is estimated that $1.5 \%$ of the adult population in the United Kingdom are currently suffering from a leg ulcer (NHS, 2020) indeed, many clinicians working in this field of practice would argue that this is a conservative estimate. When I use the word 'suffering' this is done intentionally. It is a basic human right to be free from torture (United Nations, 2020) and I would certainly imagine that suffering from a leg ulcer would feel like torture. To further compound the pain and suffering of poor lower limb health there has existed, for too long now, a culture of passivity in terms of leg ulcer management (Harding, 2016). Frequently patients within UK clinical practice are receiving sub optimal treatment when it comes to the use of compression therapy. Overuse of unrationalised 'light' or ineffective compression which contraindicates evidence-based practice, has become an epidemic within clinical practice (Hopkins, 2018). This culture is contributing to patient harm, through unwanted variations in care, sub optimal healing rates and simple ulcers deteriorating to become complex or 'chronic' wounds. For registrants of the Nursing and Midwifery Council this is a serious issue, as adjusting a prescribed therapy without a robust clinical rationale may risk patient safety (NMC 2018). This is why clinicians who are passionate about leg ulcer care are currently welcoming the introduction of the leg ulcer CQUIN, perhaps we will see a shift in the focus of leg ulcer care as it now comes under the spot light. The Commissioning for Quality and Innovation (CQUIN) (2020) scheme for 2020/21 sets out details of both the CCG and Prescribed Specialised Services schemes. The CQUIN is framed by 4 key areas; prevention of ill health, mental health, patient safety and best practice pathways. Currently leg ulcer management sits within the patient safety priority area where assessment, diagnosis and treatment of lower leg wounds are identified as an action to benefit patients with a focus on community providers of health care. The introduction of a CQUIN with a clear focus upon holistic assessment, a timely diagnosis and appropriate treatment of lower leg wounds which is underpinned by guidance from NICE (2013) is a good start and should begin to shape community practice for the benefit of patients, but there is a long way to go if we are to achieve this.

Clinicians will be required to become courageous and break the mould of sub - optimal therapy and unwanted variation in care that has existed for so long. In order to achieve this, they will need education and increased support to develop clinical practice. They will require courage and knowledge to ensure the evidence base is employed and they will need adequate education to underpin this. Thus, the development of the CQUIN must be underpinned by a commitment to funding for education in this complex area of clinical practice.

Finally, I would like to leave you with the idea that lower limb care must be recognised as a Public Health issue in the same way as other public health issues are recognised. It is time for 
leaders in lower limb management to collaborate with Public Health England, because while we begin the journey of proactively managing those who have already developed a leg ulcer, prevention of deterioration and good lower limb health education supported by a clear place for lower limbs on the public health agenda will help us to have less people developing leg ulcers in the first place.

Harding, K. (2016) Challenging passivity in venous leg ulcer care - the ABC model of management. International Wound Journal. Available at:

https://onlinelibrary.wiley.com/doi/full/10.1111/iwj.12608 (accessed 3 $3^{\text {rd }}$ February 2020).

Hopkins, A. (2018) Changing the narrative around light compression. Venous News.

Available at : https://venousnews.com/changing-the-narrative-around-light-compression/ (accessed $3^{\text {rd }}$ February 2020).

National Institute for Health and Care Excellence (NICE) (2013) Nice Guidance CGG168 Varicose Veins : diagnosis and management. Available at:

https://www.nice.org.uk/guidance/cg168 (accessed $3^{\text {rd }}$ February 2020).

The National Health Service (2020) Commissioning for quality and innovation. Available at : https://www.england.nhs.uk/wp-content/uploads/2020/01/cquin-20-21-core-guidance.pdf (accessed $3^{\text {rd }}$ February 2020).

Nursing \& Midwifery Council (NMC) (2015) The Code: Professional standards of practice and behaviour for nurses, midwives and nursing associates. London. NMC.

The United Nations (2020) What are human rights?. Available at:

https://www.un.org/en/sections/issues-depth/human-rights/ (accessed $3^{\text {rd }}$ February 2020). 